\title{
MODEL PENGEMBANGAN PERTANIAN BERKELANJUTAN DI KOTA JAMBI
}

Regional Research and Development Agency of Jambi Province

\author{
MUKHLIS
}

Badan Penelitian dan Pengembangan Daerah Provinsi Jambi

Jl. RM. Nuratmadibrata No. 1 A Telanaipura Kota Jambi

Email :mkhs6262@gmail.com

Diterima: 02 November 2019; Direvisi: 15 November 2019; Disetujui : 09 Desember 2019

https://doi.org/10.37250/newkiki.v3i2.39

\begin{abstract}
This study aims to measure the level of agricultural sustainability and design a policy scenario for sustainable agriculture development in the city of Jambi. Held in 2017 in the city of Jambi. The data obtained were analyzed using the FLAG Model approach. The results showed that the level of agricultural sustainability in Jambi City based on flag analysis included in the unsustainable category was seen from the results of the analysis that there were no green flags (sustainable/not having special concerns) and Natural Farming (NF) and Mix (CF + NF) based policy scenarios in Jambi City tends to be more sustainable. Furthermore, if agriculture in Jambi City still uses conventional Farming $(C F)$ policies with agricultural inputs that do not support sustainability, it will indicate a decreasing level of sustainability. The three urban agricultural policy scenarios, so that agriculture can be sustainable in terms of economic, social and environment, then for the City of Jambi the third scenario Mix option $(\mathrm{CF}+\mathrm{NF})$ is to collaborate between conventional quarrying with natural agriculture, among others by implementing organic farming systems, farming systems integrated and low-input farming system
\end{abstract}

Keywords: Agriculture Model, Sustainable Agriculture, Jambi City

\begin{abstract}
Abstrak
Penelitian ini bertujuan untuk mengukur tingkat keberlanjutan pertanian dan merancang skenario kebijakan pengembangan pertanian berkelanjutan di Kota Jambi. Dilaksanakan Tahun 2017 di Kota Jambi. Data yang diperoleh dianalisis dengan menggunakan pendekatan Model FLAG. Hasil penelitian menunjukkan bahwa tingkat keberlanjutan pertanian Kota Jambi berdasarkan analisis FLAG termasuk kategori tidak berkelanjutan terlihat dari hasil analisis tidak ditemukan adanya Green Flag (berkelanjutan/tidak memiliki kekhawatiran khusus) dan skenario kebijakan berbasis Natural Farming $(N F)$ dan Mix $(C F+N F)$ di Kota Jambi cenderung lebih berkelanjutan. Selanjutnya jika pertanian di Kota Jambi masih menggunakan kebijakan Convensional Farming $(C F)$ dengan input pertanian yang tidak mendukung keberlanjutan akan berindikasi pada level tingkat keberlanjutan yang semakin menurun. Dari tiga skenario kebijakan pertanian kota, agar pertanian dapat berkelanjutan dari sisi ekonomi, sosial dan lingkungan, maka untuk Kota Jambi skenario opsi ketiga Mix $(C F+N F)$, yaitu mengkolaborasikan antara pertenaian konvensional dengan pertanian alami antara lain dengan menerapkan sistem pertanian organik, sistem pertanian terpadu dan sistem pertanian rendah input.
\end{abstract}

Kata Kunci : Model Pertanian, Pertanian Berkelanjutan, Kota Jambi

\section{PENDAHULUAN}

\section{Organisation Economi Cooperation}

and Developmen (OECD) (2008),

menyatakan bahwa dalam periode 2005-

2030 permintaan akan pangan meningkat

hingga $50 \%$ didorong oleh pertumbuhan

populasi global sebesar $27 \%$ dan pertumbuhan pendapatan sebesar $83 \%$, skenario ini memiliki konsekuensi penting bagi sektor pertanian yakni: 1 . Penggunaan lahan pertanian (saat ini $40 \%$ dari total lahan yang tersedia) akan naik $10 \%$ untuk memenuhi kebutuhan yang diharapkan untuk makanan dan bahkan lebih lanjut 
jika disertakan dengan produksi energi biomassa; 2. Daerah pertanian akan tumbuh hanya $4 \%$ di wilayah sample OECD (India, Ghana, Burkina Faso, Niger dan Ecuador), tetapi sebanyak $18 \%$ di Afrika; 3. Produksi pertanian akan menjadi lebih dengan pertumbuhan produktivitas pertanian per hektar sekitar 40\%; 4. Emisi global gas rumah kaca akan meningkat $2 \%$ karena perubahan penggunaan lahan dengan variasi yang besar menurut wilayah; dan 5. Ketersediaan dan kualitas sumber daya air global akan berada di bawah tekanan yang meningkat karena proyeksi pertumbuhan produksi pertanian.

Lebih lanjut Lagi OECD menjelaskan bahwa tanpa pasar yang meringankan, respon teknologi atau kebijakan, banyak daerah akan mengalami satu atau lebih dari konsekuensi berikut: tingkat polusi tumbuh dan hilangnya keanekaragaman hayati, insiden yang lebih tinggi dari kelangkaan pangan lokal, dan peningkatan emigrasi kondisi hidup memburuk di beberapa komunitas pedesaan. Meskipun efek ini bukan saja dirasakan pada konteks regional atau lokal, namun semua bagian dari dunia akan terpengaruh. Untuk alasan ini, ada kebutuhan seluruh dunia untuk aksi kebijakan nasional dan internasional untuk menjaga pertanian menuju keberlanjutan ekonomi, lingkungan dan sosial. Selanjutnya Untung

(2006) mengidentifikasi secara rinci dampak dari praktek pembangunan pertanian konvensional yang dilakukan selama ini yaitu : 1. Peningkatan erosi permukaan, banjir dan tanah longsor; 2. Penurunan kesuburan tanah; 3. Kehilangan bahan organik tanah; 4. Salinasi air tanah danirigasi serta sedimentasi tanah; 5. Peningkatan pencemaran air dan tanah akibat pupuk kimia, pestisida, limbah domestik; 6. Eutrifikasi badan air; (g) residu pestisida dan bahan-bahan berbahaya lain di lingkungan dan makanan yang mengancam kesehatan masyarakat dan penolakan pasar; 7. Pemerosotan keanekaragaman hayati pertanian, hilangnya kearifan tradisional dan budaya tanaman lokal; 8. Kontribusi dalam proses pemanasan global; 9. Peningkatan pengangguran; 10. Penurunan lapangan kerja, peningkatan kesenjangan sosial dan jumlah petani gurem di perdesaan; 11. Peningkatan kemiskinan dan malnutrisi di perdesaan; 12. Ketergantungan petani pada pemerintah dan perusahaan/industri agrokimia.

Serikat Petani Indonesia (2016) menyatakan bahwa modernisasi pertanian dengan adanya revolusi hijau telah banyak membantu negara-negara berkembang 
untuk memenuhi kebutuhan pangan penduduknya. Tetapi keberhasilan itu memunculkan banyak hal negatif misalnya : penurunan kesuburan tanah, kerusakan hutan, hilangnya beberapa kekayaan hayati, erosi dan adanya penumpukan zatzat kimia dalam tanah.

Tuntutan dari pembangunan saat ini yang diarahkan untuk mencapai tujuan pembangunan berkelanjutan, tidak terkecuali kebijakan pembangunan pada sektor pertanian. Pembangunan berkelanjutan menurut World Comission on Economic and Development (WCED) pada tahun 1987, adalah pembangunan yang memenuhi kebutuhan generasi sekarang tanpa mengorbankan kemampuan generasi mendatang untuk memenuhi kebutuhannya. Kemudian Hersh (2006) menjelaskan bahwa pembangunan berkelanjutan menyatukan tiga faktor utama yakni : 1) Pembangunan yang memenuhi kebutuhan manusia; 2) Perlindungan dan konservasi sumber daya alam dan lingkungan; 3) Pemeliharaan kemampuan generasi mendatang untuk memenuhi kebutuhan mereka.

Agenda 21 yang menjadi komitmen pemimpin global pada KTT Bumi Rio de Jeneiro pada tahun 1992, dalam salah satu agendanya menekankan aspek yang berkaitan dengan sektor pertanian diantaranya pengelolaan lahan berkelanjutan, pengurangan dalam penggunaan bahan-bahan kimia beracun, dan penguatan peran serta petani menjadi hal yang perlu dilaksanakan oleh semua negara. Perspektif pertanian berkelanjutan secara global telah tersosialisasi sebagai arah ideal pembangunan pertanian secara global. Pertanian berkelanjutan saat ini bukan sekedar wacana, namun telah menjadi gerakan global dan harus diikuti dengan suatu tindakan nyata. Pertanian berkelanjutan telah menjadi dasar penyusunan protokol atau aturan pelaksanaan (rules of conduct) atau standar prosedur operasi dalam praktek pertanian yang baik yang dikenal dengan Good Agricultur Practices (GAP). GAP merupakan sebuah gerakan global, maka praktek pertanian berkelanjutan menjadi misi bersama komunitas internasional, negara, lembaga pembangunan, organisasi swadaya masyarakat dan lembaga konsumen internasional turut mendorong dan mengawasi pelaksanaan prinsip pertanian berkelanjutan tersebut. Sadikin (2003) menyatakan bahwa, adigium sistem pertanian berkelanjutan antara lain better environment, better farming, and better living.

Food and Agriculture Organization atau FAO (2003) menjelaskan beberapa 
fungsi dari pertanian kota sebagai : 1 . Salah satu sumber pasokan sistem pangan dan opsi ketahanan pangan rumah tangga perkotaan; 2. Salah satu kegiatan produktif untuk memanfaatkan ruang terbuka dan limbah perkotaan; 3. Salah satu sumber pendapatan dan kesempatan kerja penduduk perkotaan. Guna mengejewantahkan fungsi dari pertanian kota merupakan salah satu pekerjaan besar yang harus dihadapi seiring dengan pesatnya perkembangan Kota.

Wilayah perkotaan dihadapkan dengan berbagai permasalahan pembangunan diantaranya ledakan jumlah penduduk, konversi lahan pertanian yang semakin meningkat, pengelolaan sumber daya alam dan lingkungan yang semakin terabaikan dan lain sebagainya. Gambaran pertanian secara umum di Kota Jambi terdapat areal yang dapat dipertahan untuk areal pertanian kususnya untuk menunjang ketersediaan pangan (pertanian tanaman pangan, peternakan dan perikanan) pertanian Jika melihat perkembangan pertanian di Kota Jambi tahun 2014 dan 2015 dari beberapa komoditi diantaranya :

1. Luas padi sawah yang dipanendalam Kota Jambi pada tahun 2015 sebesar 1.490 Ha dengan produksi sebesar 2012 ton. Jika dibandingkan tahun 2014 yang luas panennya sebesar $1.381 \mathrm{Ha}$ produksi sebesar 7.186,30 ton berarti terjadi kenaikan luas panen dan penurunan nilai produksi masing-masing sebesar 7,89\% dan 72\%; 2. Untuk Palawija tahun 2015, produksi palawija seperti jagung sebesar 158,40 ton, ubi kayu sebesar 1.064,96 ton, ubi jalar 63,76 ton, dan kacang tanah sebesar 5,8 ton; 3. produksi tanaman buahbuahandi Kota Jambi seperti jeruk siam 27,46 ton, alpukat 185,6 ton, pepaya805,9 ton, dan pisang 979,7 ton, mangga dan rambutan masing-masing sebesar 211,1 ton dan 506,25 ton (BPS Kota Jambi, 2016).

Fenomena pertanian yang uraian diatas, dan sebagaimana ungkapan Smith dan Mc Donald (1998) bahwa untuk menentukan definisi filosofis keberlanjutan pertanian suatu negara merupakan hal yang relatif mudah, namun sulitnya pada penentuan definisi operasional dan metodologi untuk memungkinkan dalam pembuatan kebijakan pertanian dan perencanaan. Penelitian ini berusaha membangun definisi operasional kebijakan pertanian berkelanjutan di Kota Jambi, dengan terlebih dahulu menggunakan pendekatan metodologi yang mengukur keberlanjutan pertanian dengan indikator pembangunan berkelanjutan yakni dimensi ekonomi, sosial, dan lingkungan. Sehingga akan menghasilkan strategi pertanian berkelanjutan di Kota Jambi. 
Pertanian konvensional yang mengakibatkan berbagai permasalahan untuk keberlanjutan sektor pertanian menjadi alasan untuk menemukan strategi pertanian yang berpihak kepada alam dan aman bagi mahkluk hidup. Kota Jambi sebagai pusat pertumbuhan (growth pole), mengakibatkan semakin tergusurnya lahan pertanian. Beberapa solusi telah ditawarkan untuk mengelola pertanian kota sesuai dengan fungsinya sebagai pasokan sistem pangan dan opsi ketahanan pangan rumah tangga perkotaan, salah satu kegiatan produktif untuk memanfaatkan ruang terbuka dan limbah perkotaan, salah satu sumber pendapatan dan kesempatan kerja penduduk perkotaan (FAO 2003).

Berdasarkan latar belakang yang telah diuraikan, dapat dirumuskan permasalah dalam penelitian ini yang dinyatakan dalam beberapa pertanyaan berikut :

1. Bagaimana tingkat keberlanjutan pertanian di Kota Jambi?

2. Bagaimana skenario kebijakan pertanian berkelanjutan di Kota

Guna menjawab berbagai masalah dan fenomena yang berkembang, maka tujuan dari penelitian ini :

1. Mengukur tingkat keberlanjutan pertanian di Kota Jambi .
2. Merancang skenario kebijakan pengembangan pertanian berkelanjutan di Kota Jambi

\section{Metode Penelitian}

Penelitian Strategi Pengembangan Pertanian Kota Berkelanjutan dilaksanakan tahun 2017 di Kota Jambi. Data yang digunakan berupa data primer dan data sekunder, data primer dilakukan melalui wawancara pakar.

Analisis data pada penelitian ini dengan menggunakan pendekatan Model FLAG yang dikembangkan oleh Nijkamp et al (1991), Nijkamp dan Ouwersloot (1996), Hernandes dan Nijkmap (1998), Nijkamap (1999), Nijkamp dan Vreeker (2000), Lancker dan Nijkamp (2000), Leeuwen et al (2003), Vreeker dan Rodenburg (2003). Menggunakan indikator keberlanjutan yang disajikan dalam pita dengan label hijau, kuning, merah dan hitam dengan batas dari label warna tersebut ditentukan oleh nilai kritis atau crtitical threshold value (CTV) minimum dan maksimum (Gambar 1).

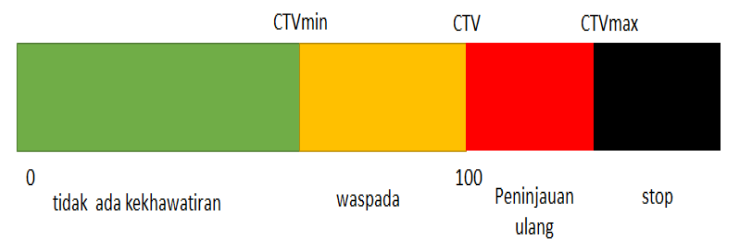

Gambar 1.

CTV Model FLAG (Nijkamp dan Vreeker 2000) 
Pada pita keberlanjutan diatas, pita hijau keberlanjutan dapat dikatakan tidak memiliki kekhawatiran khusus, sementara pita kuning menunjukkan tingkat waspada (peringatan). Pita merah mengindikasikan diperlukannya peninjauan kembali (reverse trend), sementara pita hitam mengindikasikan diperlukannya penghentian (stop). Model FLAG pada prinsipnya merupakan metode multi criteria dengan menggunakan algoritma, maksimisasi dengan kendala, atau secara matematik ditulis sebagai :

$\operatorname{Max} w=\left(x_{1}, x_{2}, x_{2}, \ldots x_{n}\right)$ dengan $x_{1} \in K_{1}, x_{2} \in K_{2}, x_{3} \in K_{3} \ldots x_{n} \in K_{n}$

Dalam konteks model FLAG nilai K1 sampai Kn diwakili oleh nilai kritis (CTV), sehingga persamaan kendala menjadi:

$$
x_{1} \in C T V_{1}, x_{2} \in C T V_{2} \ldots x_{n} \in C T V_{n}
$$

Oleh karena model FLAG adalah model multi-criteria, maka secara rinci model tersebut dapat di wakili oleh persamaan berikut :

$\max \left[\begin{array}{c}x_{1} \\ x_{2} \\ x_{3}\end{array}\right]=\left[\begin{array}{ccc}a_{1} & a_{2} & a_{1 n} \\ \vdots & \ddots & \vdots \\ a_{n 1} & \ldots & a_{n n}\end{array}\right]\left[\begin{array}{c}x_{1} \\ x_{2} \\ x_{3}\end{array}\right]=\left[\begin{array}{c}\delta_{1} \\ \delta_{2} \\ \vdots \\ \delta_{n}\end{array}\right]$

Dimana Vektor kolom $\delta_{1} \ldots \delta_{n}$ mewakili konstanta atau Critical Threshold Value (CTV). Pemenuhan skor keberlanjutan kemudian didasarkan Critical Threshold Value (CTV) dimana :
$S(x)=(C T V-x) /(C T V \min -C T V)$ untuk $x<C T V$ $S(x)=(x-C T V) /(C T V \max -C T V)$ untuk $x>C T V$

CTV yang digunakan untuk penelitian ini didasarkan pada data sekunder yang berbentuk kualitatif. Baseline data bersumber dari laporan tahunan Dinas Pertanian Peternakan Perikanan dan Kehutanan Kota Jambi Tahun 2016. Data kualitatif yang diperoleh dari Dinas Pertanian Peternakan Perikanan dan Kehutanan Kota Jambi Tahun 2016, diubah menjadi data kardinal dan kemudian menerapkan metode Regime. Metode Regime Software dapat dilakukan secara sosia1. Analisis Regim diklasifikasikan sebagai metode tidak langsung untuk data kualitatif. Hal ini merupakan fitur positif yang penting. Ketika kita menerapkan kardinalisasi data kualitatif melalui metode tidak langsung seperti Analisis Rezim, kita tidak kehilangan informasi seperti metode langsung. Hal ini disebabkan oleh fakta bahwa dalam metode langsung hanya isi teoritis dari informasi kuantitatif yang ada yang digunakan (Vreker et al. 2001). Analisis rezim ini dilakukan dengan menggunakan tools SAMISOFT,

Metode ini mendefinisikan posisi relatif satu kriteria dalam kaitannya dengan semua kriteria lainnya dengan metode perbandingan, Dengan menggunakan 
teknik matriks eigenvalue maka bobot kuantitatif dapat diberikan ke metode kriteria. Melalui pendekatan Metode Saaty (Metode Analitik Proses Hirarki/AHP) yang dikembangkan oleh Thomas Lorie Saaty pada tahun 1970an (Saaty, 1988). Metode ini didasarkan pada tiga komponen penting: 1. Artikulasi hirarkis dari unsurunsur masalah keputusan; 2. Identifikasi skema prioritas; 3. Pemeriksaan konsistensi logika dari prioritas yang diungkapkan.

Prosedur dilakukan dalam berbagai tahap. Langkah pertama terdiri dari definisi masalah dan identifikasi kriteria dalam hierarki dalam lima tingkat:

- Level 1: tujuan umum

- Level 2: kriteria

- Level 3: sub-kriteria

- Level 4: indikator

- Level 5: index

Setelah menentukan artikulasi hierarki elemen, langkah kedua dalah menentukan nilai bobot yang terkait dengan masing-masing kriteria melalui perbandingan berpasangan antara theelements. Metode SAATY menggunakan skala 9-poin semantik sebagaimana (Tabel 1), untuk mewakili dari nilai prioritas. Skala ini menghubungkan angka dengan penilaian, yang mengungkapkan kemungkinan hasil perbandingan dalam istilah kualitatif.
Melalui cara ini, elemen yang berbeda dapat dibobot dengan skala pengukuran homogen.

Tabel 1. Skala Semantik Saaty.

\begin{tabular}{|c|l|}
\hline Nilai & \multicolumn{1}{|c|}{ Definisi } \\
\hline 1 & Kepentingan yang sama \\
\hline 3 & Kepentingan sedang \\
\hline 5 & Kepentingan yang kuat \\
\hline 7 & Kepentingan sangat kuat \\
\hline 9 & Kepentingan ekstrim \\
\hline $2,4,6,8$ & Nilai perantara \\
\hline
\end{tabular}

Pada metode ini, bobot yang mewakili untuk setiap kriteria tunggal mencerminkan kepentingan setiap pihak/agen/kelompok yang terlibat dalam kebijakan tersebut mengacu pada tujuannya. Selain itu, metode ini memverifikasi kecocokan antara komponen vektor bobot dan ikatan asli. Kemudian dari matriks perbandingan berpasangan diturunkan melalui pendekatan nilai karakteristik dari vektor, adalah mungkin untuk menghitung vektor bobot yang akan digunakan untuk evaluasi dan penyelidikan selanjutnya. Akhirnya, metode ini mampu memeriksa konsistensi matriks melalui perhitungan nilai karakteristik. Pada kasus ini digunakan dalam membobotkan data kualitatif menjadi data kuantitatif indikator pertanian kota berkelanjutan di Provinsi Jambi.

Setelah menentukan bobot indikator, dirancang skenario opsi 
kebijakan yang akan dikembangkan dan dianalisis melalui FLAG Model. Pada penelitian ini dikebangkan tiga skenario kebijakan pertanian kota berkelanjutan Kota Jambi di Provinsi Jambi yakni kebijakan pertanian konvensional (KF), kebijakan pertanian Natural Farming (NF), dan kebijakan pertanian Mix (KF+NF) .

Salah satu langkah penting dalam penggunaan metode FLAG adalah penentuan ambang batas minimum dan maksium dari Critical Threshold Value atau CTV sebagaimana tabel diatas. Menurut Hermanides dan Nijkamp (1996) dan Nijkamp dan Owersloot (2000), penentuan nilai CTVmin dan CTVmax memang beragam tergantung ketersediaan data dan informasi. Jika ambang batas minimum dan maksimum dapat dketahui secara pasti dari hasil penelitian sebelumnya, maka nilai ini dapat digunakan dalam menentukan CTVmin dan CTVmax sebagaimana digunakan oleh Lancker dan Nijkamp (2000) dalam kasus analisis FLAG di Nepal. Sebaliknya jika nilai CTVmin dan CTVmax tidak diketahui dengan pasti, maka menurut Hermanides dan Nijkamp (1996) dapat diperoleh dari dua cara yakni pendapat stakeholder dan ketentuan yang telah diitetapkan dalam dokumen perencanaan. Dalam studi ini oleh karena nilai pasti tidak diketahui maka penentuan CTVmin dan CTVmax mengukuti metode yang dilakukan oleh Hermanides dan Nijkamp (1996), Nijkamp dan Owersloot (2000), serta Vreeker et al. (2001). Pada penelitian ini indikatornya berupa informasi kualitatif yang dikuantitatifkan berdasarkan indikator FLAG yang dikembangkan oleh Vreeker $e t$ al. 2001. Penentuan CTV berdasarkan skala semantik saati dengan interval CTV yang sama (3 untuk CTV min, 5 untuk CTV, dan 7 untuk CTV max) dari nilai bobot 1 sampai dengan 9, sebagaimana Tabel 3 berikut.

\section{HASIL DAN PEMBAHASAN}

Tingkat Keberlanjutan Usahatani Di Kota Jambi

\section{Hasil assessment FLAGmodel}

disajikan pada Tabel 2 :

Tabel 2

Sebaran Flag pada 3 skenario kebijakan pertanian Kota JambiCF, NF dan Mix (CF

\begin{tabular}{|l|c|c|c|}
\hline Flag & $C F$ & $N F$ & $\begin{array}{c}\text { Mix } \\
(C F+N F)\end{array}$ \\
\hline Green Fleg & 0 & 5 & 4 \\
\hline Yellow Fleg & 1 & 6 & 3 \\
\hline Red Fleg & 7 & 5 & 10 \\
\hline Black Fleg & 9 & 1 & 0 \\
\hline
\end{tabular}

Tabel 2. diatas menunjukkan hasil assessment flag model pada kebijakan pertanian Kota Jambi. Visualisasi tabel 
diatas lebih menarik diuraikan dengan Gambar 2.

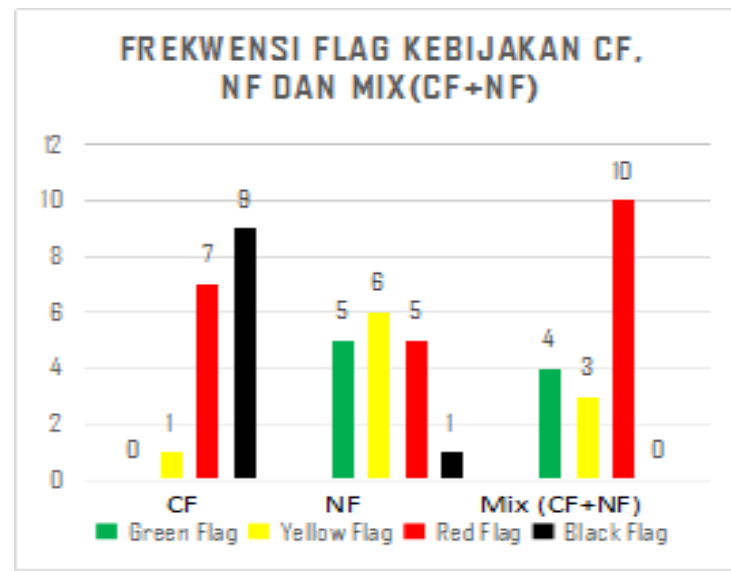

Gambar 2.

Sebaran Flag Pada Opsi Kebijakan Pertanian Kota Jambi

Gambar 2 menunjukan bahwa dalam skenario kebijakan Pertanian Konvensional $(C F)$ tidak memiliki flag hijau (tidak memiliki kekhawatiran khusus), namun terdapat 9 flag hitam (diperlukannya penghentian), 7 flag merah (diperlukan peninjauan kembali/reverse trend) dan 1 flag kuning (tingkat waspada/peringatan).

Frekuesni kemunculan flag atau bendera hitam yang lebih banyak tanpa adanya kemunculan flag hijau, menunjukkan indikasi bahwa skenario konvensional tidak berkelanjutan. Selanjutnya jika mengamati sebaran flag pada skenario kebijakan Natural Farming $(N F)$, telah terjadi penurunan frekwensi kemunculan flag hitam sebesar $89 \%$ atau hanya memiliki 1 (11\%) flag hitam. Pada skenario NFjugamemiliki bendera merah sebanyak 5 lebih sedikit jumlah bendera merahnya apabila dibandingkan dengan bendera merah yang dimiliki skenario $C F$ (71\%). Banyaknya frekwensi kemunculan bendera hijau (5 flag) menunjukkan skenario pertanian $N F$ jauh lebih berkelanjutan apabila dibandingkan dengan skenario pertanian konvensional. Skenario Pertanian Campuran $(\mathrm{Mix}(\mathrm{CF}+\mathrm{NF})$ mengalami penumpukan frekwensi penyebaran bendera dengan pita merah (tingkat waspada/peringatan) atau terbanyak jika dibandingkan dengan $C F$ dan $N F$, namun pada skenario ini memiliki flag hijau sebanyak 4 atau lebih berkelanjutan dibandingkan dengan skenario konvensional yang tidak memiliki bendera hijau.

Berdasarkan hasil di atas dapat dikatakan bahwa secara umum skenario kebijakan berbasis $N F$ dan $\operatorname{Mix}(C F+N F)$ cenderung lebih berkelanjutan walaupun masih memiliki bendera merah dan hitam. Hasil di atas juga menunjukkan jika pertanian di Kota Jambi masih menggunakan kebijakan konvensial dengan input pertanian yang tidak mendukung keberlanjutan akan berindikasi pada level keberlanjutan yang semakin menurun.

Jika keberlanjutan pertanian Kota Jambi lebih detil lagi dianalisis dengan tiga dimensi keberlanjutan yakni ekonomi, 
sosial, dan lingkungan dapat dilihat pada Gambat 3 berikut.

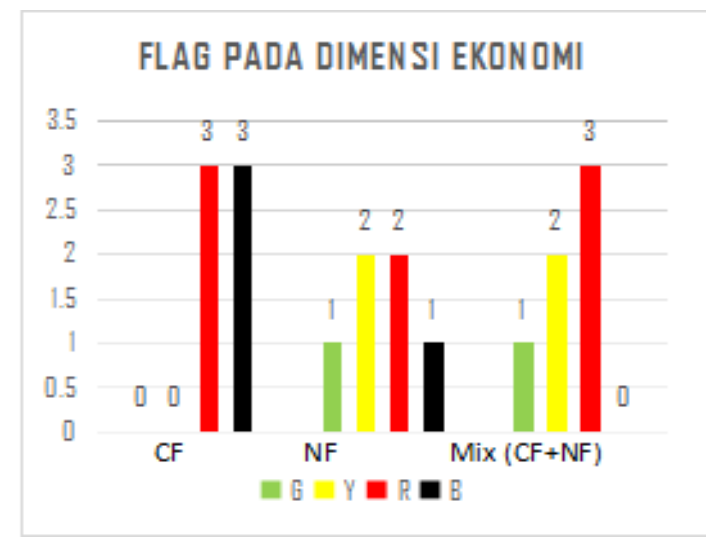

Gambar 3.

Sebaran Flag pad Dimensi Ekonomi

Pada dimensi ekonomi, terlihat

bahwa skenario kebijakan pertanian konvensional hanya memiliki sebaran bendera merah dan hitam yang masingmasing 3 flag. Sementara kebijakan pertanian natural farming hanya memiliki 1 flag hitam, 1 flag hijau dan memiliki flag merah dan kuning masing-masing 2 . Skenario kebijakan Mix $(C F+N F)$ tidak memiliki flag hitam, 3 flag merah, 2 flag kuning, dan 1 flag hijau. Ketiga skenario kebijakan yang dianalisis ini, hasil menunjukkan bahwa skenanio CFpaling tidak berkelanjutan dibandingkan dengan dua skenario lainnya $N F$ dan $M i x(C F+N F)$ yang memiliki flag merah dan hitam masing-masing berjumlah 3 , tanpa ada flag hijau yang menunjukan indikasi keberlanjutan. Sementara skenario Mix $(C F+N F)$ pada dimensi ekonomi sangat baik dengan diperlihatkan oleh tidk adanya sebaran bendera hitam, namun bendera merah tidak mengalami penurunan, walaupun pada skenario ini munculnya frekwensi sebaran bendera hijau sebanyak 1 flag yang menunjukkan indikasi yang lebih berkelanjutan dibandingkan skenario $C F$. Skenario $N F$ menunjukkan keunggulan pada dimensi ekonomi yang dibuktikan dengan sebaran bendera merah dan kuning hanya mengalami penurunan sebanyak $66 \%$ dibandingkan Mix $(C F+N F)$ dan flag hijau sama dengan Mix $(C F+N F)$ memiliki keunggulan sebesar 1 bendera hijau.

$$
\text { Pada dimensi sosial yan }
$$
ditunjukkan oleh Gambar 4 berikut, bahwa kebijakan pertanian natural farming lebih unggul dari kebijakan lainnya dengan memiliki bendera hijau $75 \%$ lebih banyak dari $M i x(C F+N F)$. Sementara kebijakan $C F$ pada dimensi sosial paling tidak berkelanjutan dibandingkan dengan dua skenario lainnya dengan memiliki sebaran bendera hijau yang paling banyak tanpa adanya sebaran bendera hijau.

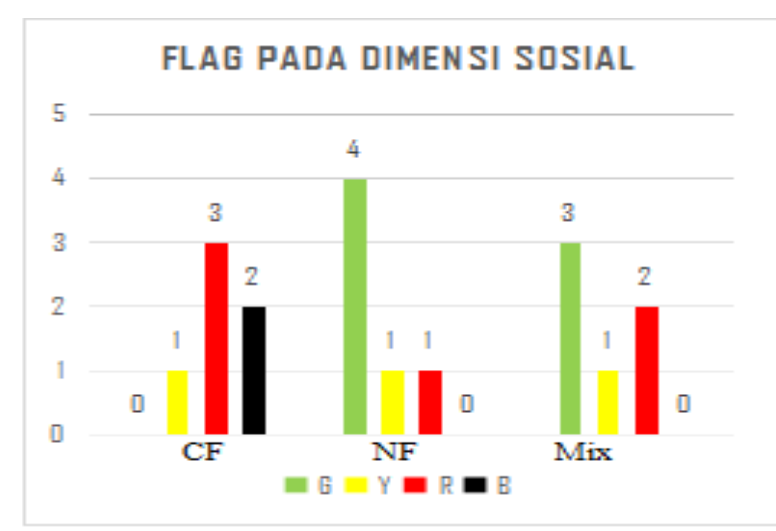

Gambar 4.

Sebaran Flag Pada Dimensi Sosial 
Gambar 4 berikut menunjukkan tingkat keberlanjutan pada dimensi lingkungan, dimana pada dimensi ini tdak ada sebaran bendera hijau dari ketiga skenario kebijakan pertanian. Hal ini menunjukkan indikasi kondisi eksisting pertanian kota saat ini pada kondisi sudah tidak berkelanjutan. Walaupun pada dimensi lingkungan ini, pada skenario $N F$ danMix $(C F+N F)$ jauh lebih baik yang dinyatakan dengan tidak adanya kemunculan bendera hitam. Pada Dimensi lingkungan terlihat bahwa kebijakan pertnian $N F$ lebih unggul yang dinyatakan oleh tidak adanya bendera hitam dan penurunan bendera merah sebesar 50\% dan bendera kuning sebesar $75 \%$.

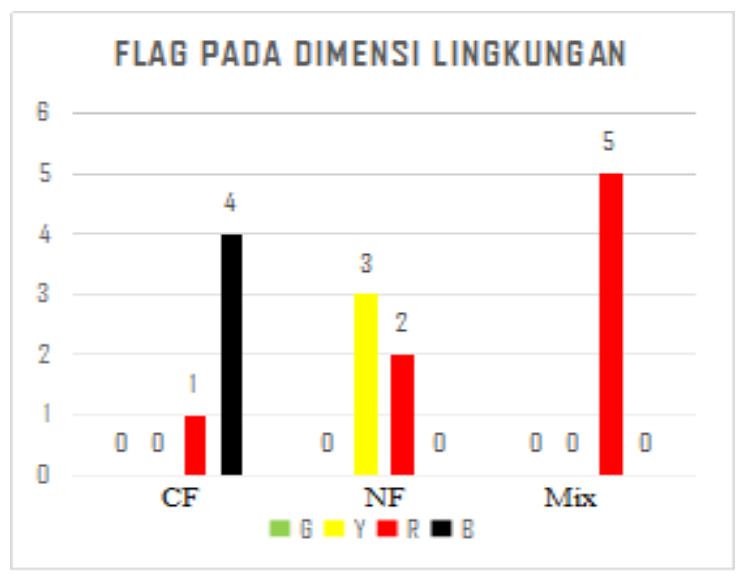

Gambar 5.

Sebaran Flag pada dimesi lingkungan

Hasil analisis model flag dapat kita lihat lebih jelas lagi perbandingan sebaran fleg pada dimensi ekonomi, sosial, dan lingkungan pada masing-masing skenario kebijak pertanian berikut ini.

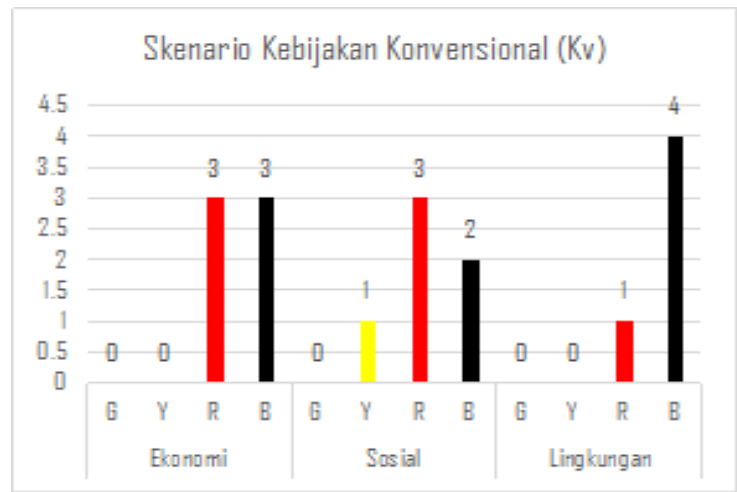

Gambar 6

Sebaran Flag pada skenario kebijakan $\mathrm{CF}$

Gambar 6. diatas menunjukkan bahwa pada ketiga dimensi keberlanjutan yakni ekonomi, sosial, dan lingkungan terlihat bahwa kebijakan petanian $C F$ tidak berkelanjutan. Hal ini diperkuat oleh analisis flag yang tidak memimiliki sebaran bendera hijau dari ketiga dimensi keberlanjutan, dan pada tiap dimensi memiliki sebaeran frekwensi flag hitam yang besar.

Selanjutnya kita amati hasil analisis flag pada skenario kebijakan $N F$ pada Gambar 7. Berikut

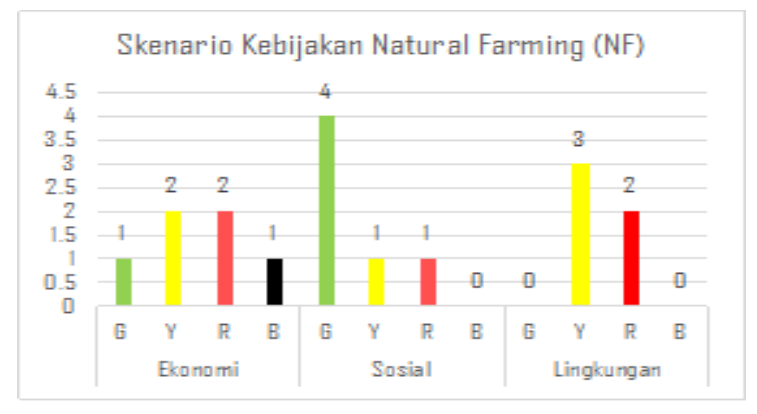

Gambar 7.

Sebaran Flag pada kebijakan $N F$

Gambar 7 diatas menunjukkan bahwa kebijakan $N F$ lebih berkelanjutan 
dengan adanya sebaran bendera hijau pada dimensi sosial dan ekonomi. Pada dimensi lingkungan memang belum terlihat sebaran bendera hija, namun sudah tidak memiliki sebaran bendera hitam. Pada dimensi ekonomi masih memiliki sebaran bendera hitam, hal ini dapat dipahami dengan kondisi pertanian kota saat ini atau yang diwakili oleh kebijakan $C F$ sudah tidak berkelanjutan. Kebijakan NF lebih menekankan keberlanjutan pada dimensi sosial dan lingkungan, namun tidak mengabaikan dimensi ekonomi. Hal ini sangat mendukung amanah pembangunan berkelanjutan yang bertujuan untuk melaksanakan pembangunan ekonomi dan sosial tanpa mengabaikan kelestarian lingkungan.

Selanjutnya kita tinjau analisis keberlanjutan skenario kebijakan $\operatorname{Mix}(C F+N F)$. Pada Gambar 8 terlihat bahwa kebijakan pertanian $\operatorname{Mix}(C F+N F)$ juga lebih berkelanjutan dibandingkan dengan $C F$. Terlihat bahw tidak ada lagi sebaran bendera hitam pada dimensi ekonomi, sosial, dan lingkungan. Namun pada dimensi lingkungan hanya memiliki bendera merah yang sebarannya sangat besar atau 5 flag. Tentunya ini dapat dipahami bahwa kebijakan pertanian $\operatorname{Mix}(C F+N F)$ tidak terlalu menekankan pada tujuan kelestarian lingkungan atau masih berbasis ekonomi, walaupun telah memperhatikan dimensi sosial dan lingkungan.

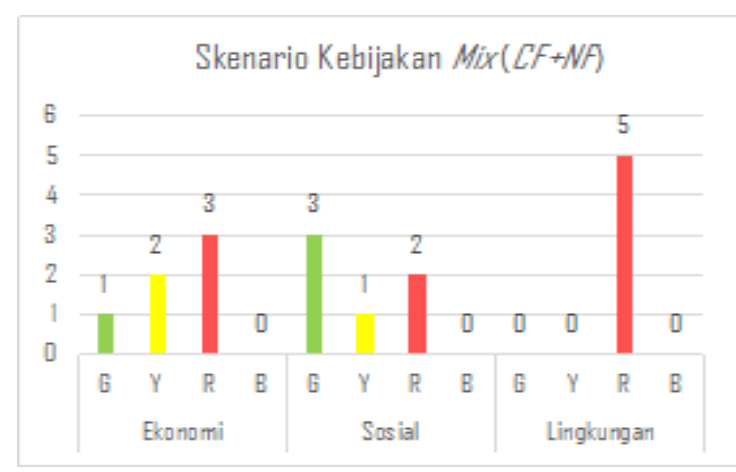

Gambar 8.

Sebaran Flag Pada KebijakanMix $(C F+N F)$

Tabel 3. berikut menyajikan hasil tabulasi silang untuk ketiga skenario pertanian $(C F, \quad N F$, dan $\operatorname{Mix}(C F+N F)$ dengan merujuk pada model flag Nijkam \& Vreeker (2000) dan Erlinda (2016). Tabulasi silang bertujuan untuk membandingkan dua skenario berdasarkan frekwensi Flag dan dua skenario berpasangan atau pairwise comparism (Erlinda, 2016). Sebagaimana terlihat pada Tabel 3.

Tabel 3.

tabulasi silang untuk ketiga skenario pertanian $(C F, N F$, dan $M i x(C F+N F)$

\begin{tabular}{|c|c|c|c|c|c|c|}
\hline \multicolumn{1}{|c|}{} & \multicolumn{7}{|c|}{$N F$} & \multicolumn{1}{c|}{} \\
\cline { 2 - 7 } & & $G$ & $Y$ & $R$ & $B$ & \\
\cline { 2 - 7 }$C F$ & $G$ & 0 & 0 & 0 & 0 & 0 \\
\cline { 2 - 7 } & $Y$ & 1 & 0 & 0 & 0 & 1 \\
\cline { 2 - 7 } & $R$ & 3 & 3 & 1 & 0 & 7 \\
\hline & $B$ & 1 & 3 & 4 & 1 & 9 \\
\hline & Tot & 5 & 6 & 5 & 1 & 17 \\
\hline
\end{tabular}




\begin{tabular}{|c|c|c|c|c|c|c|}
\hline \multirow{4}{*}{$C F$} & \multicolumn{7}{|c|}{$\operatorname{Mix}(\mathrm{C} F+N F)$} & Total \\
\cline { 2 - 7 } & & $G$ & $Y$ & $R$ & $B$ & \\
\cline { 2 - 7 } & $G$ & 0 & 0 & 0 & 0 & 0 \\
\cline { 2 - 7 } & $Y$ & 0 & 1 & 0 & 0 & 1 \\
\cline { 2 - 7 } & $R$ & 2 & 1 & 4 & 0 & 7 \\
\cline { 2 - 7 } & $B$ & 2 & 1 & 6 & 0 & 9 \\
\cline { 2 - 7 } & Tot & 4 & 3 & 10 & 0 & 17 \\
\hline
\end{tabular}

\begin{tabular}{|c|c|c|c|c|c|c|}
\hline \multirow{4}{*}{$N F$} & \multicolumn{7}{|c|}{$\operatorname{Mix}(\mathrm{C} F+N F)$} & Total \\
\cline { 2 - 7 } & & $G$ & $Y$ & $R$ & $B$ & \\
\cline { 2 - 7 } & $G$ & 3 & 1 & 1 & 0 & 5 \\
\cline { 2 - 7 } & $Y$ & 0 & 1 & 5 & 0 & 6 \\
\cline { 2 - 7 } & $R$ & 1 & 1 & 3 & 0 & 5 \\
\cline { 2 - 7 } & $B$ & 0 & 0 & 1 & 0 & 1 \\
\cline { 2 - 7 } & Total & 4 & 3 & 10 & 0 & 17 \\
\hline
\end{tabular}

Tabel 3 diatas menyajikan tabulasi silang antara tiga skenario kebijakan pertanian. Kebijakan NFlebih unggul dari kebijakan $C F$ dan kebijakan $\operatorname{Mix}(C F+N F)$ dengan ditunjukkan oleh lebih banyak bendera hijau $(5 ; 0)$ dan $(5: 4)$. Kemudian kebijakan $\operatorname{Mix}(C F+N F) \quad$ memiliki keunggulan dari skenario $C F$ dengan lebih banyak bendera hijau (4:0). Dengan demikian skenario $N F$ menjadi opsi pilihan terbaik untuk kebijakan pertanian berkelanjutan dibandingkan opsi kebijakan $C F$ dan kebijakan Mix $(C F+N F)$.

\section{Kesimpulan}

1. Tingkat keberlanjutan pertanian Kota Jambi berdasarkan analisis fleg termasuk kategori tidak berkelanjutan terlihat dari hasil analisis tidak ditemukan adanya green fleg.

2. Skenario kebijakan berbasis Natural
Farming $\quad(N F)$ dan Kebijakan Gabungan (Pertanian konvensional dengan pertanian alami)/Mix $(C F+N F)$ di Kota Jambi cenderung lebih berkelanjutan walaupun masih memiliki bendera merah dan hitam, jika pertanian kebijakan pertanian konvensional $(C F)$ tetap dipertahankan akan mengakibatkan tingkat keberlanjutan semakin menurun.

3. Jika pertanian di Kota Jambi masih menggunakan kebijakan Pertanian Konvesional $(\mathrm{CF})$ dengan input pertanian yang tidak mendukung keberlanjutan akan berindikasi pada level keberlanjutan yang semakin menurun

\section{Saran}

Dari tiga skenario kebijakan pertanian kota, untuk Kota Jambi agar pertanian dapat berkelanjutan berkelanjutan yang dilihat dari sisi ekonomi, sosial dan lingkungan, maka untuk Kota Jambi skenario opsi ketiga $\operatorname{Mix}(C F+N F)$ yaitu mengkolaborasikan antara pertenaian konvensional dengan pertanian alami antara lain dengan menerapkan sitem pertanian organic dan pertanian rendah input. 


\section{DAFTAR PUSTAKA}

Badan Pusat Statistik Kota Jambi. 2016. Kota Jambi dalam angka.

Erlinda, N. 2016. Pembangunan wilayah berkelnjutan di Provinsi Jambi dan Implikasi Model JAMRUD. Disertasi Pascasarjana IPB, Bogor, Indonesia

Hersh M. 2006. Mathematical Modelling for Sustainable Development. Springer-Verlag, Berlin.

Nijkamp P, Lasehait P, Soeteman F. 1991. Sustainable Development in a Regional System. Research Memorandum. 93, Vrije Universiteit, Amsterdam.

Nijkamp P, Ouwersloot H. 1996. A Decision Support System for Regional Sustainable Development: The FLAG Model. Vreij University, Amsterdam.

Nijkamp P. 1999. Environmental security and sustainability in natural resource management. In S Lonergan (editor), (Ed) Environmental Change, Adaptation and Security (pp. 377395). Kluwer, Dordrecht.

Nijkamp P, Vreeker R. 2000. METHODS :Sustainability assessment of development skenarios: methodology and application to Thailand. Ecological Economics 33, 7-27, Elsevier.

OECD. 2008. OECD Contribution to the United Nationals Commision on Sustainable Developmen 16: Towards Sustainable

Agriculture.www.oecd.org/publishing/ corrigenda. Diakses Desember 2016.

Smith, C.S., Mc Donald, G.T. 1998. Assessing the sustainabilityof agriculture at the planning stage. J. Environ. Manag. 52,15- 37.

Untung, K. 2006. Penerapan Pertanian Berkelanjutan untuk Meningkatkan Ketahanan Pangan. http://kasumbogo.staff.ugm.ac.id/inde x.php

Vreeker, R, P. Nijkamp, C.T. Welle. 2001. A Multicriteria Decision Suport Methodology for Evaluating Airport Expansion Plans. Tinbergen Institute Discussion Paper. TI 2001-005/3. Department of Spatial Economics Free University Amsterdam De Boelelaan 11051081 HV Amsterdam The Netherlan 